\title{
Human Rights-Based Approach to Reducing Preventable Maternal Deaths in Ghana: A Six-year Review of Media Reports
}

\author{
Renee Aku Sitsofe Morhe \\ (Corresponding Author) \\ Department of Private Law, College of Humanities and Social Sciences, KNUST, Ghana \\ reneemorhe@yahoo.co.uk \\ Felix Kwame Sosoo \\ Department of Modern Languages, School of Languages, \\ University of Ghana, Legon, Ghana \\ Emmanuel Komla Senanu Morhe \\ Department of Obstetrics and Gynaecology, University \\ of Health and Allied Sciences, Ghana \\ DOI//http://dx.doi.org/10.4314/gjds.v16i3.7
}

\begin{abstract}
This paper sought to ascertain the extent to which litigation is highlighted in reports on maternal deaths in the Ghanaian media. Using internet search we reviewed reports on maternal death in the media from January, 2013 to December, 2018. Thematic analyses of the reports that satisfied the inclusion/exclusion criteria were performed. It was established that healthcare leaders and key state personalities have through the media created good public awareness about unacceptably high maternal deaths in the country. The root causes were highlighted. Only few case reports were presented and there had been scanty emphasis on using legal means of addressing the problem of inadequate access as a human rights violation. In conclusion rights-based approach to addressing poor maternal health challenges in Ghana is grossly underutilized. Stakeholders are encouraged to include the option of using legal redress as a means of ensuring government and healthcare providers keep their promise of providing quality maternity care to reduce preventable deaths of women.
\end{abstract}

Keywords: Ghana, Litigation, Rights-Based Approach, Maternal Health, Media Reports 


\section{INTRODUCTION}

Access to quality maternal health to reduce morbidity and mortality of women in the prime of their lives, remains a major public health challenge despite the world's technological advancement. Maternal health is the health of women during pregnancy, childbirth and the postpartum period or within 42 days of termination of pregnancy (WHO, 2018). Pregnancy is a physiological state needed for perpetuation of humankind. However, every pregnancy carries some risk for the woman. Thus, ensuring access to quality healthcare is essential to their wellbeing and ultimately development of a healthy society. Adopting human rights approach to addressing the root causes of lack of access offers hope to reduction of the preventable deaths. The World Health Organization gives clear guidelines on what governments, policy makers and implementers as well as civil society need to do to reduce maternal morbidity and mortality (WHO, 2018).

It is the ultimate responsibility of the country to establish and run a healthcare system that assures safety of pregnancy and childbirth. Inadequate access to healthcare results in most maternal deaths occurring in developing countries, particularly sub-Saharan African countries (WHO, 2018). The poor and socially disadvantaged women who live in rural communities that lack basic social infrastructure are disproportionately affected (Abor, Nkrumah, Sakyi, Adjasi \& Abor, 2011). Hence, access to maternal healthcare is a human rights issue (Katzive, 2010; Yamin \& Maine, 1999; Odallo, Opondo \& Onyango 2018). The African Commission on Human and Peoples Rights also declared the issue of poor maternal health as not only a developmental issue but a matter of human rights (ACHPR/ Res 135(XXXXIIII), 2008; Maputo Protocol, 2003). Yet, women in sub-Saharan Africa and for that matter women in Ghana, continue to lose their lives when pregnant (Atuoye, Dixon, Rishworth, Galaa, Boamah \& Luginaah 2015).

Domestic laws like the Constitution of Ghana guarantees everyone the fundamental human right to life and the right to have access to optimum healthcare. Article 13 of the Ghana 1992 Constitution mandates that no one should be deprived of the right to life. Also article 27 prescribes that special care should be accorded women during a reasonable period before and after child-birth during which periods working mothers are permitted to have paid leave. Internationally, the Convention on Elimination of all forms of Discrimination against Women (CEDAW, 1981) grants reproductive rights including the right to maternal health; and CEDAW's Optional Protocol enables women assert and claim this right. CEDAW mandates that all countries including Ghana pass legislation granting human rights listed in the document, like right to maternal health, to women. Ghana is a party to CEDAW 
and its Optional Protocol and is expected to have laws and policies that ensure attainment of reproductive rights.

A study carried out by Asamoah et al. (2011) found that causes of maternal deaths in Ghana include haemorrhage, abortion, hypertensive disorders, miscarriage, obstructed labour and sepsis. Some of the underlying factors for these causes as given by Thaddeus and Maine (1994) are (1) delay of women in seeking medical attention, (2) delay in arriving at health facilities usually due to bad transportation systems and (3) delay at health facilities usually due to shortage of staff and facilities. The last two underlying factors are the focus of this paper because they impinge on responsibility of the government to grant maternal health as a human right. Whenever there is maternal mortality or morbidity due to these factors, there is said to be failure on the part of the government to provide access to healthcare. In any such event, the Optional Protocol to CEDAW will find the government in breach of its international obligations and when remedy is not offered to the victim, litigation can be brought to compensate them. Litigation is therefore a human rights-based approach to reducing preventable maternal deaths. Litigation has many benefits because apart from offering financial remedy for injury or death, it also raises awareness about the need for the government to redress factors like infrastructure which may not get the necessary attention when polices and strategies are being drawn up or implemented on maternal health.

In developing policies and strategies to reduce maternal mortality however, litigation has not been highlighted as an intervention measure. Following WHO and other best practice guidelines, Ghana has developed policies on unrestricted access to safe motherhood, family planning, gender-based violence and other reproductive health services (GHS, 2015). Thus, the country has instituted interventions in improving access to health including provision of community hospitals or Community-based Health Planning and Services (CHPS) compounds (Der, Moyer, Gyasi, Akosa, Tettey, Akakpo, Blankson \& Anim 2013). The CHPS programme is to improve access to primary healthcare in rural areas. By the close of 2015, Ghana had made some gains in reducing maternal mortality through adopting measures to meet targets of the Millennium Development Goals (MDGs) (UNDP 2015). Nonetheless, the reduction had been slow, and the country failed to the meet the MDG-5 target of reducing maternal mortality by three-quarters. In 2015, the national maternal mortality was about 319 per 100,000 live births, which is high for a country that has attained middle income status (Apanga \& Awoonor, 2018). Hopefully, with diligent implementation of strategies of the Sustainable Development Goals, further reduction of maternal mortality could be expected. 
As it stands now, employing litigation as a rights-based approach is very necessary. The United Nations observes that improvement of maternal health requires nations of the world upholding fundamental human rights including reproductive rights by respecting international treaties, protocols and national constitutions (Hunt, 2016). Human rights are inalienable rights that all human beings are born with. These include the right to life, liberty and property. All human beings are endowed with inalienable natural rights (Offei, 2013). It goes without saying that pregnancy is a very natural and basic function of humankind and lack of access to maternal health amounts to violation of the right to life of women. In India for example, the High Court held that the right to life in the Indian Constitution means that a woman had the constitutional right to survive pregnancy (CHARM versus State of Bihar, 2011). This is a good precedence for other developing nations to emulate in critical examination of the persistence of preventable and avoidable maternal deaths.

The human rights-based approach guides countries and government agencies to be accountable and transparent to the people they serve. The government agencies in the context of this paper include institutions that implement healthcare policies on behalf of the government. We contend that in most parts of the world including Ghana, there are judicial and quasi-judicial organs offering local and international remedies for violations of the right to maternal health. At the international level, the Committee on Elimination of Discrimination against Women provides a forum for litigation which has been used to claim compensation from governments who are found liable for lack of access to maternal health (Mesquita \& Kismödi, 2012). At the local level, the Ghana Commission on Human Rights and Administrative Justice (CHRAJ), domestic courts, as well as disciplinary committees of professional bodies are local avenues to seek redress of human right violations in healthcare practice. The question is how well informed is civil society in Ghana about the existence of litigation through these channels as redress for violation of the right to maternal healthcare?

The media serves as the mouthpiece and a good source of information for the people. This paper therefore reviewed print and electronic media reports on maternal mortality in Ghana. The objective of this paper is to determine contributory factors to maternal death and ways of seeking redress highlighted in Ghanaian media reports. The paper further ascertained the extent to which media reports emphasized litigation or legal redress as a strategy under the human rights approach to improving maternal healthcare to reduce associated morbidity and mortality. The purpose of the paper is to highlight litigation as human rights-based approach to improving access to quality maternal healthcare. Hopefully, the paper is expected to add to knowledge in the area and set the stage for empirical research 
in this important area of law and healthcare. The findings and recommendations on the way forward will be useful in maternal health policy implementation and enforcement in Ghana and other developing countries.

\section{THE CONTEXTUAL FRAMEWORK}

Traditionally, the Common Law in Ghana provides redress at the law courts for preventable maternal death. The redress comes under the law on medical negligence, which places duty on all health institutions and medical professionals to observe due care when involved in activities that could harm patients (Bolam versus Friern Hospital Management Committee, 1957 \& Bolitho versus City and Hackney Health Authority, 1997). In laying down the Common Law rule on the standard of care required from professional persons (Medical Research Council and others versus Touray, 1995-96), the Gambian Court of Appeal per Chomba, Justice of the Court of Appeal, noted that the standard of care demanded from medical practitioners would be that required from any professional person. Medical professionals are therefore expected to act with requisite skill and competence, failing which they and their institutions can be found liable under Ghanaian law (Gyan versus Ashanti Goldfields Corporation, 1991). Medical negligence cases can be litigated up to the highest appellate court in Ghana, the Supreme Court. Arbitration in medical negligence cases can also be offered by the Ghana Medical and Dental Council and the Nursing and Midwifery Council. These professional bodies have disciplinary committees that censure members for ethics violations but sometimes intervene in highly publicised cases of medical negligence. Medical negligence however is only one factor accounting for preventable maternal deaths.

Among other factors accounting for preventable maternal deaths are systemic failures partly due to failure of governments to develop good transportation network rendering some settlements geographically inaccessible to healthcare centres (Apanga \& Awoonor, 2018). There is also poor distribution of health facilities and skill attendants as well as inadequate allocation of resources (Atuoye et al., 2015). The problem is that the Common Law does not provide remedy where death is the result of these socio-economic factors. In such cases, recourse to human rights-based approach to maternal health using the principle of legal accountability through litigation is the best option for remedy. The approach uses the country's commitments to international human rights standards on the right to maternal health, to provide remedy.

Generally, the approach identifies holders or beneficiaries of a particular human right, and the duty bearers of the right. The duty bearers in the area of human 
rights are the government and its agents who must make sure that those rights are enjoyed. The human rights-based approach also identifies the obligations of governments as the duty bearer to provide remedy or to ensure that remedy is provided to victims or rights' bearers whose rights have been violated. The rightsbased approach therefore empowers rights bearers to claim rights and encourages and assists duty bearers to fulfill their obligations. As exhibited in Figure 1 below, litigation is a major element in the rights-based approach to improving maternal health. It is the obligation of governments to provide remedy when there is preventable death or morbidity as the result of lack of access to maternal health care. This paper focuses on litigation for preventable maternal death due to factors other than professional negligence. These factors are lack of accessible roads, inadequate facilities and staffing. The rights-based approach to maternal health identifies women as holders of the right to maternal health and the government and its agents as the duty bearers.

Standards on maternal health are established under various human rights documents including the Protocol to the African Charter on Human and Peoples Rights (2003), the International Covenant on Economic, Social and Cultural Rights (1977) and CEDAW (1979). Cumulatively, these documents impose the obligation on government and its organs to respect, protect and fulfil women's rights to maternal health care. Legal accountability for maternal health through litigation is established under the Optional Protocol to CEDAW. Ghana is a party to the Protocol. The Protocol provides avenue for litigation for violation of the right to maternal health and recognises various forums for redress in maternal health cases, locally and at the international level before the treaty-monitoring body - the Committee on Elimination of Discrimination against Women. The Committee, in one of the earliest cases held before it, Alyne da Silva Pimentel Teixeira versus Brazil (2008), concluded that Brazil was liable for the death of a pregnant woman who could not afford a private ambulance and was made to wait in critical condition for 8 hours before transported to a municipal hospital where there were no beds available. She was kept in the emergency room hallway and died the next day.

The Ghanaian Constitution under article 27 mandates the government to accord special care to mothers during a reasonable period before and after birth. The obligation goes beyond ante-natal and post-natal care, like maternity leave and nutrition for mothers, to include the due diligence obligation to monitor the actions of private healthcare providers in provision of the highest standard of health for all especially the disadvantaged and vulnerable. The obligation extends to provision of accessible and well equipped hospitals and healthcare centres and involves provision of effective remedy and reparation to victims when systems and structures fail. 
Traditionally however, socio-economic rights like healthcare have been very difficult to obtain (Issah Iddi Abass \& 10 Others versus Accra Metropolitan Assembly \& Anor, Unreported; Soobramoney versus Minister of Health, 1998). The difficulty is that government obligation to achieve socio-economic rights 'progressively' and 'subject to availability of resources' contributed to the problem of irreverence given to socioeconomic rights under domestic law. Although State practice has been to support the equal status and importance of socio-economic rights and civil and political rights, unlike civil and political rights, there is usually failure within domestic law to take steps to provide effective means of redress to individuals or groups alleging violations of socio-economic rights. The above traditional difficulty has now been addressed not only through the litigation offered by the Optional Protocol but also Ghanaian case law that holds socio-economic rights justiciable (Ghana Lotto Operators Association \& others versus National Lottery Authority; 2007).

Local remedies in Ghana can be obtained from both the Commission on Human Rights and Administrative Justice (CHRAJ) and the human rights division of the High Court. These constitutional bodies help in providing remedy for human rights violations and they provide redress in situations where the Common Law fails, like cases involving maternal death due to socio-economic factors. Local remedies must however be exhausted before recourse is made to the international forum, in order to prevent duplication of efforts and forum shopping. The only exception is where there is deliberate delay in the national courts or where the court processes are unreasonably prolonged or unlikely to bring effective relief. In Uganda, litigating maternal death cases as human rights violations under the rights-based approach has promoted good maternal health in the country (Dunn, Lesyna \& Zaret 2017; Centre for Health Human Rights \& Development v. Attorney General, 2012).

It is the obligation of government to educate and advice victims on measures to take when there is preventable death or morbidity as the result of lack of access to maternal health care. The media continue to publish stories of maternal mortality due to causes other than medical negligence. These causes include inaccessible and ill-equipped hospitals and lack of staff and yet there is no emphasis on possible avenues of litigation of such cases before the human rights court or CHRAJ. There is a need to create awareness, educate and advice victims on the option of litigation under the human rights-based approach. In Ghana, documentation at health facilities about causes of maternal deaths relating to medical negligence or medical complications are common but causes of death reports do not contain much detail about other causes like bad roads, lack of ambulance or lack of adequate medical staff (Asamoah et al., 2011). 
Media reports however provide information on these causes and on failure of the government to provide infrastructure and accessible healthcare facilities to ensure optimum maternal health. In this regard, various forms of media stories are the best available sources of information for ordinary members of society for informed opinion and remedial measures to be taken.

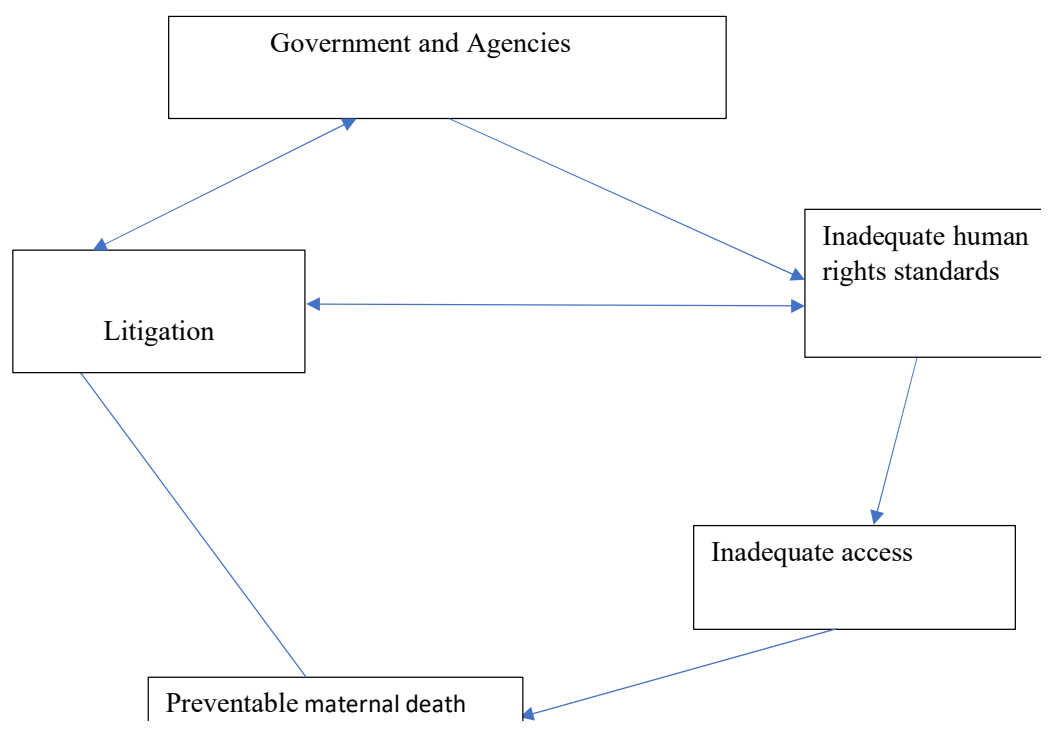

\section{Figure 1: Contextual framework on rights-based approach to reducing preventable maternal deaths}

Source: Authors' Construct, 2019

\section{METHODOLOGY}

Desk review and qualitative analysis of maternal deaths reports in the Ghanaian print and electronic media was performed. The review was based on media reports instead of research papers or hospital reports because while the latter is likely to be more detailed and possibly more accurate, it is less likely to be available to civil society for critical examination and informed opinion and action. Additionally, in a society like Ghana where there is media freedom and pluralism, we believe that information in media reports on a topical issue like maternal mortality from political actors, policy makers, healthcare services providers and end users would largely reflect the prevailing contributory factors and local means of seeking redress. We also believe that the success of adopting human rights-based approach to improving maternal health basically depends on actions and commitments of individuals in civil society; notably, judges and policy enforcement agents whose 
opinion and decisions about unacceptable nature of maternal healthcare can lead to finding lasting solutions to the problem in the country.

\section{Search Words}

The key words used in our search were Ghana, maternal health, maternal death, maternal mortality, maternal morbidity, death of pregnant women, rights-based approach, human rights violations in pregnancy, reproductive rights, and maternal health stakeholders.

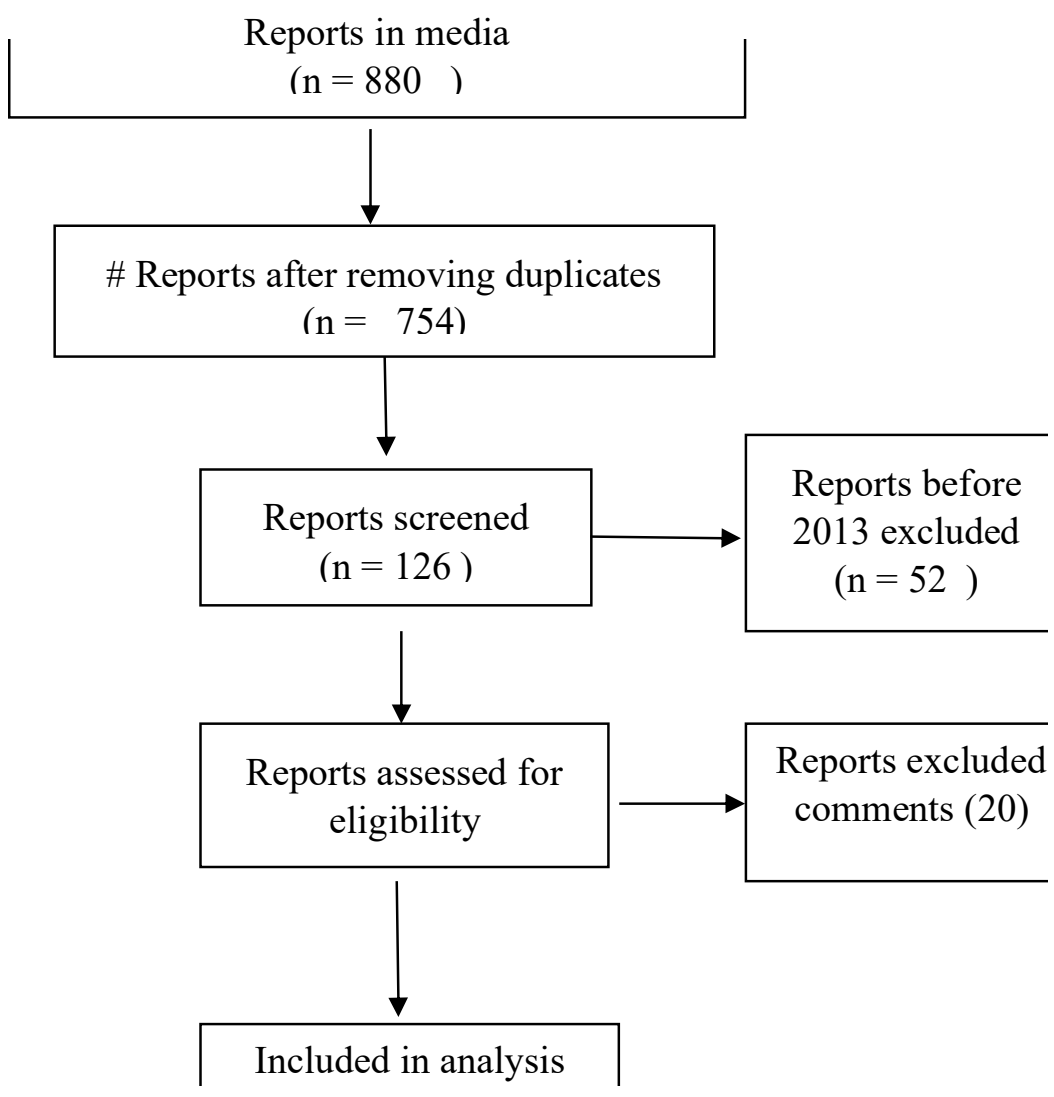

$$
(\mathrm{n}=54)
$$

\section{Figure 2: Inclusion/exclusion criteria}

Source: The PRISMA Group, 2009

\section{Sources of Data}

This internet search reviewed reports and documentaries on maternal health in three state owned media including Ghana News Agency, Daily Graphic and Mirror, The New Times Corporation (Ghanaian Times and The Spectator), and five leading 
private media including Ghanaweb, Daily Guide, The Statesman, Myjoyonline and videos and documentaries on the Ghana Maternal Health Channel.

\section{Search Strategy}

Two reviewers independently performed the search from the relevant media archives from the websites. The media were purposively selected based on national readability and coverage. We largely employed PRISMA guidelines for systematic review by the PRISMA Group (2009).

\section{Inclusion/Exclusion Criteria}

The review of the media reports on maternal deaths was limited to a six-year period of January 2013 to December, 2018. Reports before and after the selected period of review were excluded. Similarly, reports included in the review were those published in the media that is available on the internet.

Report screening selection process: We thoroughly read through the headlines of the reports and selected those that satisfy our inclusion criteria. We excluded duplicate copies of the reports after examination of the reports for consistency. Reports published before 2013 and after 2018 were excluded.

\section{Data Processing and Analysis}

The selected reports were read thoroughly looking out for key messages given to civil society. We performed thematic analysis of the reports. Themes and subthemes on attributable factors to maternal deaths and ways of addressing the problem in the country were carefully noted. We examined the reports for highlights of the key elements of rights-based approach to improving access to maternal health to prevent morbidity and mortality. These include accountability, transparency, nondiscrimination, participation and empowerment, sustainability and international cooperation. We read individual case reports thoroughly for evidence of using legal process of perceived human right violations. We present the findings and discuss how human rights approach can be used to optimize access to maternal healthcare in Ghana within the existing local and international legal provisions.

Stakeholders of maternal healthcare as used in this review include the Ministry of Health as a policy maker, and Ghana Health Services, teaching hospitals, faith based or mission hospitals and clinics as well as private healthcare providers who offer services to the people on behalf of Government of Ghana. All these institutions operate under policy guidelines of the Ministry of Health. Another important stakeholder is the judicial and quasi-judicial organs such as Health Services 
Regulatory Authority, Medical and Dental Council, Nursing and Midwifery Council, Pharmacy Council and Food and Drugs Authority. These agencies enforce the law, policy, standards and protocols on maternal health. Equally important stakeholders in ensuring access to maternity care are the end users in the community and the multilateral and non-governmental organizations.

\section{RESULTS}

\section{Causes and Preventive strategies of Maternal Deaths in Ghanaian Media}

The media reports gave a picture of the high incidence of maternal mortality, the causes and policy interventions but did not refer to litigation as a remedy for some preventable maternal deaths. All news media analysed carried coverage of presentations of reports on the state of maternal health in Ghana. Such reports were presented by key healthcare leaders and experts from facility, district, regional and national levels of service delivery in the country. The reports gave statistical picture of the problem; and consistently indicated that maternal mortality is unacceptably high. For instance, in 2015 and 2016 the Greater Accra Region was reported to record 208 and 197 maternal deaths representing maternal mortality rates of 117 and 180.4 per100,00o live births respectively (myjoyonline.com, 2017).

Major medical causes often reported included haemorrhage, hypertensive disorders in pregnancy, unsafe abortion, infections, obstructed labour and anaemia. The reports, captioned under a number of worrying headlines from various media houses indicating tragic and pathetic nature of maternal death, came from all regions of the country (Daily Guide Africa, 2014; Ghanaweb.com, 2018; Daily Guide, 2017). 
Table 1: Maternal death attributable factors highlighted in the media

\begin{tabular}{|c|c|c|}
\hline Main theme & Sub-theme & Solutions highlighted \\
\hline $\begin{array}{l}\text { Maternal death a public } \\
\text { problem }\end{array}$ & $\begin{array}{l}\text { - } \quad \text { Causes of maternal death } \\
\text { - magnitude }\end{array}$ & - Stakeholder concerns \\
\hline $\begin{array}{l}\text { Poor maternity care } \\
\text { attendance }\end{array}$ & 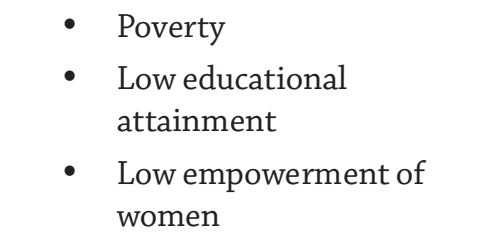 & $\begin{array}{ll}\text { - } & \text { Reducing poverty } \\
\text { - } & \text { Girl-child education } \\
\text { - } & \text { Women empowerment } \\
\text { - } & \text { Healthcare financing }\end{array}$ \\
\hline $\begin{array}{l}\text { Inadequate accessibility } \\
\text { of health facilities }\end{array}$ & 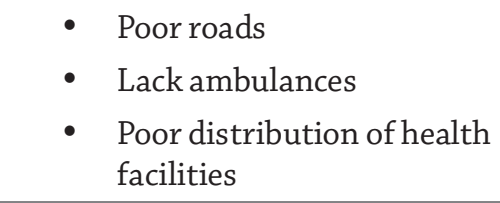 & - Stakeholder appeals \\
\hline $\begin{array}{l}\text { Inadequate material and } \\
\text { skilled human resources }\end{array}$ & $\begin{array}{l}\text { - Inadequate infrastructure } \\
\text { - Shortage of bed } \\
\text { - Shortage of supplies } \\
\text { - Inadequate equipment } \\
\text { - Lack of trained personnel }\end{array}$ & 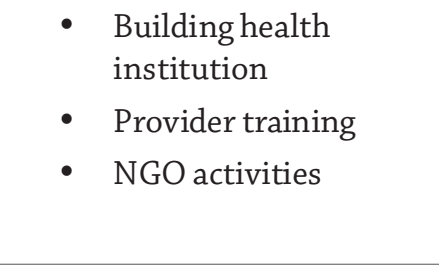 \\
\hline $\begin{array}{l}\text { Poor access to skilled } \\
\text { provider in health facility }\end{array}$ & $\begin{array}{l}\text { - Inadequate care in health } \\
\text { facility } \\
\text { - } \text { Poor provider attitude } \\
\text { - Stakeholder outcries }\end{array}$ & 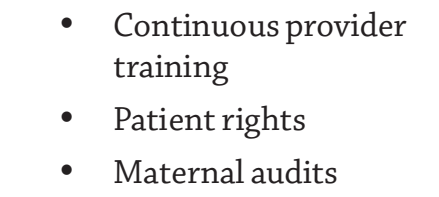 \\
\hline
\end{tabular}

Various factors leading to the maternal deaths were well highlighted by the media. Most of the reports were health facility reports that dwelt mainly on causes and the mortality ratios. These were followed by opinion article and reports on interviews of experts in the field of maternity care. These include physicians, obstetricians, reproductive health practitioners and activists, midwives, health facility heads and directors of Ghana Health Service and the Ministry of Health. As already known, factors implicated in causes of maternal deaths in the country could be grouped under three levels of delay in receiving the needed maternity care (Thaddeus and Maine, 1994). Only 4 individual case reports were included in the analysis.

\section{Poverty and Low empowerment of Women}

Attendance at antenatal care was said to be influenced by poverty, low educational attainment, low empowerment of women and religious beliefs in the community. Several reports carried appeals to the public and pregnant women and their partners to seek care early in pregnancy labour and delivery to reduce maternal morbidity and mortality. The clarion call on women to seek skilled care and introduction of the Free Maternity Care programme under donor support as well as the National 
Health Insurance Scheme were reported to have culminated in increased health facility attendance of pregnant women.

\section{Health Facility Accessibility: Transportation Challenges}

Most media reports carry information on transportation challenges in getting to health facilities. Notably, poor road infrastructure and inadequate ambulance services were extensively covered in the media reports. Transportation of pregnant and labouring women to emergency care centres in taxis and on motorbikes on rough and rugged roads had been frequently reported. Lack of hospitals with basic obstetrics care causing women in rural areas to trek long distances to access maternal healthcare were frequently reported (Ghanaweb.com, 2016).

There were reports on construction and commissioning of health facilities from various parts of the country. This included construction and development of CHPS compounds through cooperation and assistance agencies from developed countries and United Nations specialized agencies working in development to enhance access to maternal health. A CHPS compound is meant to improve access to maternal health in underserved rural communities. However, some reports conveyed lack of political will to fully implement and support this home-grown strategy to improve access to maternal health in less privileged communities. Reports revealed that some CHPS compounds remain closed in certain communities because of shortage of funds, medical supplies and health professionals particularly, midwives. The CHPS compounds are run with internally generated funds that are often not adequate because of lack of commitment from some District Assemblies. Many of the compounds have been reported to depend on donor agencies like the United States Agency for International Development (USAID) for survival. The media carry opinion articles about the need to develop CHPS concept (Ghanaweb.com, April 24th, 2018).

\section{Inadequate Material and Human resources}

Delays occurred at health facility level where emergency care was not delivered promptly. There were multiple reports about shortage of skilled personnel in various hospitals and clinics. Skewed distribution of specialists and trained personnel in favour of cities and urban centres has been well documented with frequent appeals to healthcare professionals to accept postings to rural communities. This level of delay was frequently reported and attributed to inadequate number of trained staff, negative health staff attitude, inadequate medical support services such as blood bank and laboratory service, lack of emergency equipment and even lack of bed and consumables (Ghanaweb.com, 2018). The congestion and lack of bed with associated delay, patient discomfort, morbidity and mortality was so rampant in emergency 
care centres in major hospitals that the media captioned it "no bed syndrome" (Graphic Online, June 16, 2018; Daily Guide Network, June 13 2018; Myjoyonline. com, June 14, 2018).

\section{Measures to Address the Problem}

There were reports on public-private partnership and international collaborations in pre-service and in-service training of diverse groups of healthcare varied providers at various levels to improve accessibility of skilled care. Clear strategy to address inequity in the distribution of skilled staff was not presented in the reports.

\section{Legal redress of Perceived Human Right Violations}

There were inadequate reports on prosecutions or settlements of cases that involved maternal heath rights violations, in the courts or before CHRAJ. Accountability, transparency, equity and non-discrimination, the key elements of litigation under the rights-based approach were not well articulated in the media coverage of presentations of maternal mortality. Reports that emphasize responsibility of the government and its agencies were scarce. In one such report the speaker clearly stated that: "there has been a marked lessening of efforts to address maternal deaths and this cannot be ignored. We need to identify where the loopholes are and bring pressure to bear on everyone who has a role to play. There are issues with infrastructure and human resource across the country; these need to be addressed at the national budgeting level" (Daily Graphic, April 21st, 2014).

Ways of seeking redress of perceived maternal health right violations by aggrieved parties were rarely featured in the reports. There were little information or clear strategies presented in the media to inform civil society about obligations of governments under the international human rights instruments granting maternal health. Another speaker indicated: "we must prioritise our funding needs. Every year, we talk about the statistics as though the lives of these women are just numbers. They are mothers, wives, sisters and breadwinners. We need to take a step back and examine the impact of the strategies being implemented by the Ministry of Health and the Ghana Health Service" (myjoyonline.com, April 8th, 2014).

Also, there were little information from experts on how countries could address gaps in their responsibilities to assure the people, particularly women of their safety in pregnancy, labour and delivery. Indeed, media reports revealed that CHRAJ showed concern about the slow pace of the country in meeting its millennium development goals on reduction of maternal deaths (Ghana News Agency, 2013). Reports also revealed that CHRAJ expressed the need for pragmatic maternal health interventions to be taken to achieve the goals. There was however no information on litigation as a means of redress. 
Regarding quality improvement measures to reduce maternal mortality, media reports did reflect national adoption of many strategies in line with human rights approach to maternal health in the country. These strategies often outlined by healthcare leaders and experts were reported to include ensuring transparency and inclusiveness in policy making and structuring of service delivery to promote equity and non-discrimination. Media reports reflected wide consultations with multiple stakeholders on maternal health. However, these interventions appear not to have the desired impact as implied by a speaker at a maternal health forum: "without sounding alarmist, something is definitely not right. We are building CHPS compounds, there is free maternal healthcare, there are various sensitisation programmes taking place in communities and yet we keep recording these mortalities. There is something wrong somewhere" (myjoyonline.com, April 8th, 2014).

\section{Individual Case Reports in the Media}

Detailed reports on individual cases of clear reproductive and human rights violations in provision of quality maternal health care at all levels of responsibility were scarce. There were four individual case reports on maternal deaths that were perceived to have occurred under unacceptable circumstances. Most of these lacked follow up reports making it difficult to track the outcome of the stories. We present the following cases to illustrate the factors leading to reported maternal deaths. For confidentiality we excluded specific identifies of the cases.

Case 1: A pregnant woman was reported to have gone into pre-term labour. Her husband did not know the number of the ambulance service to call and tried transporting her to the hospital in a taxi. On the way she delivered in the taxi and started bleeding profusely. When they got to the nearest hospital, no emergency interventions were instituted but they were told to go to the next hospital. Unfortunately, the woman died on their way before they could get to the hospital (Age of woman and region unknown) (Maternal Health Channel, 2013).

Case 2: A 28-year-old woman delivered in a community; that was developed for people displaced by the construction of a hydroelectric dam; and began bleeding. The husband put her in a taxi to transport her to the nearest hospital on a road over the hydroelectricity dam. This road links the community to the hospital but has a security gate that was shut at night. When they got to the dam, the gate was locked by the attendant who was not available at the time. It took about an hour for him to come to open the gate for them. They eventually got to the hospital after at least three hours when she was weak and in bad state. The doctor on duty was said not to be available. Attempts made by the nursing staff to save her were unsuccessful 
and she passed away. There was a lot of public out-cry over this case culminating in Supreme Court Judge, Justice Dotse, chastising political leaders for not addressing such issues (Torgome, Volta Region. Maternal Health Channel, August 14th, 2013).

Case 3: A 24-year old pregnant woman in Accra was allegedly given shabby treatment by some officers at a hospital. Her sister alleged that doctors and nurses would not give her a bed to lie on when she complained of backache. Because no bed was available she was reluctantly given drip in a wheel chair and some medication after which she asked to be taken to another hospital even though she was weak. She was taken by her family to a private hospital from where they were referred to the gynaecology department of a referral hospital. She died shortly after her arrival at the hospital. Her family asked that the appropriate authorities take action against the doctors and nurses on duty at the time (Korle-Bu, Greater Accra Region. Daily Guide Africa, March 5th, 2014).

Case 4: A 30-year-old woman in Ashanti Region went into labour and reported to an urban hospital. After sometime in labour, she was told she needed a caesarean section. However, the operation was allegedly delayed over payment of some money and lack of theatre space. The undue delay resulted in the death of the woman and the unborn baby. Ghana Health service was said to have instituted a probe into this case (Suntreso, Ashanti Region. Pulse TV News, November 7 th, 2018).

\section{DISCUSSION}

The media reports in this review clearly show that maternal mortality remains a major public health problem in Ghana. The findings are consistent with the observation that among the factors impinging on optimum advancement and enjoyment of maternal healthcare in Ghana are poor health service infrastructure, inadequate material and human resources and inaccessibility of hospitals and clinics due to poor roads, lack of ambulances and other safe vehicles for transportation (Owusu-Sarpong, Boamah \& Baiden 2017). The cases presented clearly illustrate the various levels of delay and inadequacy of the health delivery system to provide comprehensive care of pregnant women.

Cases 1 and 2 illustrate inadequacy of transportation system, and inaccessibility and shortfalls of services at hospitals and clinics, which are mainly responsibilities of the government. Case 3 and 4 show delay in getting to a hospital, lack of bed and inadequate care in first hospital of call, delay in diagnosing the problem and the lack of capacity in the second hospital and ultimately delay in receiving the needed care. 
All the cases show shortage of material and human resources at the health facilities, negative staff attitudes and insufficient care at the emergency care delivery point. These among others suggest violations of the right to health and life of pregnant women. The various strategies with political support have proved too little to give hope to civil society. As observed from the Ghanaweb.com report (2018) on CHPS compounds, poor development of the CHPS programme is an indication of poor access to primary health care including maternal health in rural areas. This implies inequity and discrimination of health service delivery to people in rural communities who are mostly peasant farmers that contribute greatly to the development of the country. This observation is not in line with the elements of rights-based approach to ensuring access to health guaranteed by the national constitution and CEDAW and the Optional Protocol.

As illustrated in Case 3, the media reports also show that maternal deaths are often due to late referrals from hospitals and clinics. This finding is also consistent with the literature on maternal health in Ghana (Thaddeus \& Maine 1994; Senah, 2003). It underscores the need to improve the referral system that is essential for provision of optimum maternal health. Without doubt, maternal deaths from inefficient referral system due to lack of ambulances and good public transport in some parts of the country and many bad roads in the rural areas (Apanga \& Awoonor-Williams, 2018) are violations of fundamental human rights that require some accountability. Interventions to avoid ensuing legal suits or litigations will help a great deal in improving access and quality of care in the health delivery system of the country.

Scanty media reports on the general outcome of maternal mortality audits do not help civil society including healthcare providers who need such crucial evidence for informed decision making (World Bank, 2011). Although details of audit reports are not expected in the media because they are traditionally for institutional improvement, making broad findings public for accountability and transparency of service delivery to the community will inure to the benefit of all stakeholders. Indeed, maternal death surveillance varies from one country to another (Creanga, 2017). A good surveillance system provides learning opportunities to prevent future maternal deaths. Maternal health surveillance and facility based maternal death or mortality audits which are institutional interventions to improve quality of care and which have been in Ghana since 2000 ought to be strengthened.

Further, local ways of interrogating attributable causes of death need exploration and modification for adoption as a cost effective way of developing a community based maternal death audit system. Indeed, many local level maternal mortality review committees could be established under District Assemblies to inform and empower community members to interrogate the causes and associated factors and 
present a viable way of addressing the problem. Community based maternal death audit or community based surveillance of maternal deaths is an effective way of identifying causes of maternal deaths and attributable factors (Adomako, Asare, Ofosu, Iott, Anthony, Momoh \& Anderson 2016).

It is an approach to indirectly inform community members of measures they can take to reduce maternal deaths. It also equips them on the right questions to ask regarding the cause of deaths and attributable factors in their communities. It also helps community members feel part of the process of improving maternal health to reduce morbidity and mortality of women and their babies. Regarding community based monitoring, women participation is very important. Maternal health policies are more effective when women are involved in the formulation, implementation and appraisal processes.

Participation in interventions affords women access to the necessary information that affects their reproductive health and rights. They are empowered when they play active roles in decision making and implementation of policies relating to their health. Women's empowerment is paramount in rights-based approach to improving quality of maternal health (Pratley, 2016). It is fundamental to seeking skilled birth attendance, demanding explanations and reasons for what the care provider does. Additionally, the public health division of the Ministry of Health could establish a maternal mortality and morbidity watch group in all health institutions, both public and private, to document and monitor incidents and patient complaints regarding lack of access to maternal care for possible action. Such a measure would not only assist the country to give better care but will also save the government costly law suits.

With respect to the overarching need for sustainability of maternal health policies and the responsibility of government in relation to resources at health facilities treating women, the government needs to ensure proper management of healthcare funds and ensure that donor funds are not tainted by corruption, which hampers interventions for optimum maternal healthcare. Corruption is a strong underlying preventable factor for reducing maternal mortality (Centre for Reproductive Rights, 2008). Addressing corruption to ensure that health facilities are well resourced to provide quality care, will motivate pregnant women to patronise facilities and seek skilled attendance.

The media stories also revealed that not much is known about legal redress or litigation because numerous media reports on maternal mortality highlighted very little on constitutional provisions on the rights of women and their families and opportunities for redress if they feel aggrieved. It is conceivable that litigation for 
maternal death at the human rights court could be affected by traditional barriers to accessing justice like the complex and costly court processes (Lewis, 2011). There is therefore the need for pro bono and experienced legal aid lawyers in the field of sexual health rights and reproductive justice. Many cases litigated before the Committee on Elimination of Discrimination against Women, were brought by pro bono lawyers and interest groups and non-governmental organizations, both domestic and international.

The case of Alyne da Silva Pimentel Teixeira versus Brazil for example was brought before the Committee on behalf of the deceased by pro bono lawyers from two human rights organizations; the Centre for Reproductive Rights and Advocacia Cidada pelos Directos Humanos. Apart from precedence from Uganda previously mentioned, Ghanaian non-governmental human rights organizations can also take inspiration from Kenya where the Centre for Reproductive Rights institutes public interest litigation to address human rights violations in relation to maternal health (Odallo et al., 2018).

Part of the CHARJ's mandate is to educate the public and civil society on human rights and fundamental freedoms including maternal health rights. However, the media reports show the gap in this education especially on domestic modes of redress for obligations accrued at international level.

CHRAJ is the best forum for litigating maternal death cases because it does not charge for its services. CHRAJ should set up a maternal mortality monitoring group from among its lawyers. Formation of such a group will be at no additional cost to the country because the members would be lawyers already working at CHRAJ. This group of lawyers could collaborate with the various maternal mortality audit teams set up by the Ministry of Health. Based on audit teams report, CHRAJ could initiate fact-finding missions and make specific recommendations to the government on how best to meet standards set under the constitution and the various human rights documents granting the right to maternal health.

Similar work has been done by the Kenyan National Commission on Human Rights which monitors the realization of economic, social and cultural rights in the country and the Australian Human Rights and Equal Opportunity Commission which has a well - developed practice of inquiry into systemic violations of human rights, especially economic, social and cultural rights (United Nations, 2005). Maternal health is optimised when there are not only laws but also remedies that protect the right to maternal health by adequately preventing, protecting and compensating women whose right or access to maternal health is violated. 
Litigation on maternal death has dual benefits. On one hand, much as the government and its agencies may consider such disputes as causing financial loss, in the long-term healthcare providers including administrators and managers will learn from their mistakes and improve on the quality of care they offer. This will eventually lead to greater client satisfaction, higher patronage and increased productivity, growth and development of national institutions of health. On the other hand, any compensation paid to the aggrieved party ultimately goes to take care of the family, particularly children. Civil society should be made aware of their rights and where there are violations, individuals should be free to seek redress at whatever level. Adequate accountability and transparency in accounting for every death is paramount in building society confidence in the healthcare delivery system and in acceptability of locally available services.

\section{CONCLUSION}

Human rights-based approach to maternal health includes the assurance of remedy for unfair maternal death or morbidity at both local and international levels. Rights and litigation awareness are very essential for the way forward in securing quality maternal healthcare rights to prevent maternal deaths. The Ghanaian media has stories and reports on commonness of maternal deaths that occur as result of lack of access to maternal healthcare but not much on the right to seek redress of perceived human right violations in relation to the deaths. Apart from creating awareness and providing remedy to victims, litigation enables healthcare providers and managers learn from their mistakes and improve quality of care leading to general improved maternal health and less mortality. Hopefully, this paper has highlighted legal redress or litigation as a strategy under the rights-based approach to claiming maternal health rights to eradicate wrongful mortality and morbidity. Adopting this strategy will undoubtedly keep the government and healthcare providers at all levels in check to provide services according to evidence-based standards and protocols.

\section{RECOMMENDATION}

The study has established the need for litigation as a human rights-based approach to ensuring accountability in access to maternal health. Since litigation can be a costly process, it is recommended that CHRAJ take up the advocacy in this area and litigate cases on behalf of women. It is also recommend that lawyers involved in pro bono work provide free legal aid service for women who suffer mortality or morbidity due to inadequate access to maternal health care. 


\section{REFERENCES}

Abor, P., Nkrumah, G., Sakyi K., Adjasi, C. and Abor, J. (2011). The socio-economic determinants of maternal health care utilization in Ghana. International Journal of Social Economics, 38(7), pp. 628-648.

ACHPR/Res 135 (XXXXIIII) (2008). Resolution on Maternal Mortality in Africa.

Adomako, J., Asare, G.Q., Ofosu, A., Iott, B.E., Anthony, T., Momoh, A.S. and Anderson F.W. (2016). Community-based surveillance of maternal deaths in rural Ghana. Bulletin of the World Health Organization, 94(2), pp. 86-91.

Alyne da Silva Pimentel Teixeira versus Brazil (2009). CEDAW/C/49/D/17.

Apanga, P.A. and Awoonor-Williams J.K. (2018). Maternal death in rural Ghana: A Case Study in the Upper East Region of Ghana, Front. Public Health, (Case Report) 6(101), pp 1-6.

Asamoah, B.O., Moussa, K.M., Stafstrom, M., and Musinguzi, G. (2011). Distribution of causes of maternal mortality among different socio-demographic groups in Ghana; a descriptive study. BMC Public Health. 11(159), pp. 1-17.

Atuoye, K.N., Dixon J., Rishworth A., Galaa S.Z., Boamah S.A., and Luginaah I. (2015). Can she make it? Transportation barriers to accessing maternal and child health care services in rural Ghana. BMC Health Services Research. 15 (333), pp. 1-10.

Bueno de Mesquita J., and Kismödi E. (2012). Maternal mortality and human rights: landmark decision by United Nations human rights body. Bulletin of the World Health Organization (online). Available at https://www.who.int/bulletin/ volumes/90/2/11-101410/en/. Accessed 11th November, 2018.

Centre for Health Human Rights \& Development \& 3 Ors v Attorney General (2012). Constitutional Petition No.16 of 2011. UGCC 4.

Centre for Reproductive Rights (2008). Broken Promises. Human Rights, Accountability, and Maternal Deaths in Nigeria (online). Available at: www.who.int/pmnch/ topics/maternal/crr_broken_promises.pdf. Accessed 11th November, 2018.

CHARM v. State of Bihar and Others (2011). C.W.J.C. No. 7650 (online). Available at:www.reproductiverights.org/sites/crr.civicactions.net/files/documents/ CHA. Accessed 31st October, 2018.

Creanga, A.A. (2017). Maternal mortality in the developed world: a review of surveillance methods, levels and causes of maternal deaths during 2006-2010. Minerva Ginecol. 69(6), pp. 6o8-617. 
Daily Graphic/Ghana (2014). Institutional maternal deaths high (online). Available at: www.graphic.com.gh/news/general-news. Accessed 2nd December, 2018.

Daily Guide Africa (2014). Maternal death on the rise in Volta (online). Available at: www.newsghana.com.gh. Accessed on 12th September, 2018.

Daily Guide (2017). Maternal deaths rise at KATH again (online). Available at: www. ghheadlines.com/agency/daily-guide/20170928/56469011. Accessed 7 th September, 2018.

Der, E.M., Moyer, C., Gyasi, R.K., Akosa, A.B., Tettey, Y., Akakpo, P. K., Blankson, A. and Anim, J. T. (2013). Pregnancy related causes of deaths in Ghana: a 5-year retrospective study. Ghana Medical Journal, 47(4), pp.158-163.

Dunn, J.T, Lesyna K. and Zaret A. (2017). The role of human rights litigation in improving access to reproductive health care and achieving reductions in maternal mortality. BMC Pregnancy Childbirth. 17(2): 367, pp. 70-158.

Ghana News Agency (2013). Using birth stools to reduce maternal deaths (online). Available at: www.ghananewsagency.org/features/using-birthing-stool-toreduce-maternal-deaths-a-must-for-ghana-55883. Accessed 5th November, 2018.

Ghana Health Service (2016). Reproductive Health Policy, 2015 (online). Accra, Ghana: Available at: ghanahealthservice.org/division. Accessed 23rd November, 2018.

Ghanaweb.com (2018). 30 Pregnant women dead in Eastern Region between January to May 2018 (online). Available at: www.ghanaweb.com/NewsArchive/ Accessed 2nd December, 2018.

Ghanaweb.com (2016). Bad roads killing pregnant women in Central Region (online). Available at: ghanaweb.com/GhanaHomePage/NewsArchive/-473824; 01-102016. Accessed 6th September, 2018.

Ghanaweb.com (2018). Midwives in Upper East decry working without gloves, other basic tools (online). Available at: ghanaweb.com/ Date: 2018-05-02, Accessed 5th November 5, 2018.

Ghanaweb.com (2018). The Community-Based Health Planning and Service (CHPS) Concept in Ghana (online). Available at: www.ghanaweb.com/GhanaHomePage/ features/The-Community-Based-Health-Planning-and-Service-CHPSconcept-in-Ghana-646058. Accessed 5th November 5, 2018.

Ghana Commission on Human Rights and Administrative Justice (2014) State of the Human Rights Report (online), Available at: chraj.gov.gh/wp-content/ uploads/2018/o8/2013-SOHR-REPORT.pdf. Accessed 12th September, 2018. 
Hunt, P. (2016). Interpreting the International Right to Health in a Human RightsBased Approach to Health. Health and Human Rights, 18(2), pp. 109-130.

Katzive, L. (2010). Maternal Mortality and Human Rights. American Society of International Law, 104, pp. 383-385.

Lewis, R. (2011). Litigation Costs and Before-the-Event Insurance: The Key to Access to Justice? The Modern Law Review, 74(2), pp. 272-286.

Maternal Health Channel (2013). Torgome Maternal Death at the Supreme Court (online). Available at: www.mhcghana.com/av/83ec612bf1. Accessed 6th September, 2018.

Maternal Health Channel (2013). This Week We Are Calling 193 for an Ambulance! (online). Available at: http://www.mhcghana.com/Programmes/131. Accessed 5th September, 2018.

Myjoyonline.com news (2017). Greater Accra tops in maternal deaths (online). Available at: www.myjoyonline.com/news/2017/april-6th. Accessed 1st December, 2018.

Odallo, B., Opondo, E., and Onyango, M. (2018). Litigating to ensure access to quality maternal health care for women and girls in Kenya. Reproductive Health Matters, 26(53), pp. 123-129.

Offei, S. (2003). Jurisprudence and Legal Philosophy. London: The ComFRALS Publishing, p. 85 .

Owusu-Sarpong, A., Boamah, K.A. and Baiden, F. (2017). Associated Factors and Quality of Care Received among Maternal Deaths at a Regional Hospital in Ghana: Maternal Death Audit Review. Afr J Reprod Health, 21(2), pp. 49-54.

Pratley, P. (2016). Associations between quantitative measures of women's empowerment and access to care and health status for mothers and their children: A systematic review of evidence from the developing world. Soc Sci Med., 69, pp. 119-131.

Senah, K. (2003). Maternal mortality in Ghana: The other side, Institute of African Studies Research Review: 2003 19(1): pp. 47-56.

Thaddeus, S. and Maine, D. (1994). Too far to walk: Maternal mortality in context. $J$ Soc Sci Med 38(8), pp. 1091-1110.

UNDP (2015). Ghana Millennium Development Goals (online). Available at:www.gh.undp. org/content/ghana/en/home/library/poverty/2015-ghana-millenniumdevelopment-goals-report.html. Accessed 1oth September, 2018. 
United Nations (2005). Economic, Social and Cultural Rights Handbook for National Human Rights Institutions (online). Available at: www.ohchr.org/Documents/ Publications/training12en.pdf. Accessed 1oth September, 2018.

World Health Organization (2018). Maternal health. Making childbirth a positive experience (online). Available at: www.who.int/maternal-health/en/. Accessed 11th November, 2018.

World Health Organization (2018). Maternal mortality (online). Available at www. who.int/news-room/fact-sheets/detail/maternal-mortality. Accessed 1oth September, 2018.

World Health Organization (2016). Maternal Mortality (online). Available at: www. who.int/mediacentre/factsheets/fs348/en/. Accessed 3rd January, 2017.

World Bank (2011). Maternal Death Audit as a Tool Reducing Maternal Mortality (online). Available at: siteresources.worldbank.org/INTPRH/ Resources/3763741278599377733/MaternalDeathAuditMarch22011.pdf. Accessed 8th September, 2018.

Yamin, A., and Maine, D. (1999). Maternal mortality as a human rights issue: Measuring compliance with international treaty obligations. Human Rights Quarterly, 21(3), pp. 563-607. 